\title{
Nematicidal Activity of Lantana Camara L. for Control of Root-Knot Nematodes
}

\author{
Ganesh Ghimire $^{1}$, Ranjana Gupta ${ }^{1}$ and Arvind K Keshari ${ }^{2}$ \\ 1 Central Department of Zoology, Tribhuvan University, Kirtipur, Kathmandu, Nepal \\ 2 Patan Multiple Campus, Tribhuvan University, Lalitpur, Kathmandu, Nepal
}

\begin{abstract}
Various concentrations of aqueous leaf extract of Lantana camara L. were assessed against second stage juveniles $\left(\mathrm{J}_{2}\right)$ of Meloidogyne spp. (Goeldi, 1982) for its nematicidal potency in vitro conditions. Study showed 50\% concentration of Lantana camara leaf extract at $48 \mathrm{hrs}$ of incubation period and above showed effective in immobilizing second stage of larvae $\left(\mathrm{J}_{2}\right)$ of Meloidogyne spp. The standard concentration ' $S$ ' (100\%) of leaf extract was found to be highly nematostatic, $98.66 \%$ of nematode were found dead in $48 \mathrm{hrs}$. Similarly, 57.66\% of nematode juveniles were found dead when applied 50\% concentration in $48 \mathrm{hrs}$. Mean number of $\left(\mathrm{J}_{2}\right)$ dead at $100 \%$ concentration for three time period was statistically significant highest at $48 \mathrm{hrs}$. So far, $50 \%$ concentration in $48 \mathrm{hrs}$ and above was appropriate for controlling the root-knot nematode which seems as an alternative to chemical pesticides.
\end{abstract}

Keywords: Concentration, Leaf extract, Meloidogyne, Nematostatic, Second stage juveniles $\left(\mathrm{J}_{2}\right)$

\section{Introduction}

One of the most damaging groups of plant nematodes is the root-knot nematode (Meloidogyne spp.). It is an obligate root parasite of more than 200 plant species including vegetable, horticulture and woody plants (Hussey 1985). Root-knot nematode, Meloidogyne spp. (Goeldi, 1982) (Tylenchida: Heteroderidae) is a major plant-parasitic nematode species affecting the quantity and quality of the crop production in many annual and perennial crops. Infected plants show typical symptoms including root galling, stunting and nutrient deficiency, particularly nitrogen deficiency (Siddiqui et al. 2001). In Nepal, the root-knot nematode is considered as the major problem for many agriculture crops (Manandhar and Amatya 1988, Keshari 2004). Therefore, the control of root-knot nematodes is very important to enhance plant productivity. Since, the chemical pesticides cause hazard to the biodiversity, therefore, the use of botanical pesticides can be better option to control root-knot nematodes.

\section{Materials and Methods}

\section{Study Area}

The proposed study area for the research was Kirtipur Municipality of the Kathmandu district. Kirtipur is one of the recently urbanized cities of Kathmandu valley located to South-west of the central Kathmandu. It extends from $27^{\circ} 41^{\prime} 36^{\prime \prime}-27^{\circ} 38^{\prime} 37^{\prime \prime} \mathrm{N}$ to $85^{\circ} 18^{\prime} 00^{\prime \prime}-85^{\circ} 14^{\prime} 64^{\prime \prime} \mathrm{E}$ and has 1300 to 1402 meter of altitudinal range from sea level (Fig. 1).

Nepalese Journal of Zoology | Online Volume 3 Issue 1 | November 2015 | Page 1 


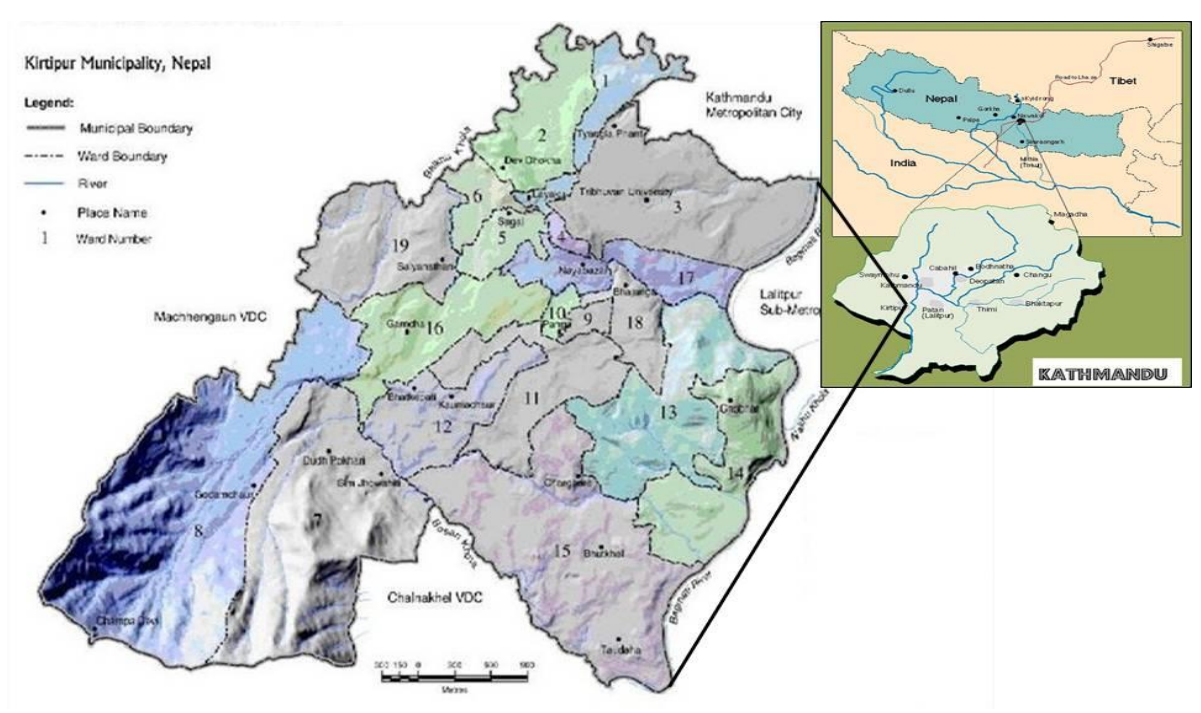

Figure 1. Map of Nepal and study area.

\section{Plant material}

Lantana camara L.used for the experiment was collected from natural habitats of Kirtipur. The study was conducted in laboratory of Central Department of Biotechnology and Central Department of Zoology. The study was conducted from December 2012 to September 2013.

\section{Preparation and storage of aqueous leaf extract}

Fresh mature healthy leaves of Lantana camara were washed and air dried using an oven at $28^{\circ} \mathrm{C}$. The dried leaves were ground using a Classic Maraja Electric Blinder. A $250 \mathrm{gm}$ of fine powder was dissolved in $1000 \mathrm{ml}$ sterilized $\mathrm{DH}_{2} \mathrm{O}(1 \mathrm{gm} / 4 \mathrm{ml}$ basis$)$. Aqueous suspension was allowed to soak on Stvart Orbital Shaker at room temperature for $24 \mathrm{hrs}$ for the extraction of active ingredients and then passed through two folds of muslin cloth followed by filtration through Whatman no.1 filter paper. The filtrate obtained so far was centrifuged at $2400 \mathrm{rpm}$ for $10 \mathrm{~min}$ and clear supernatant was stored at $4^{\circ} \mathrm{C}$ in a plastic container as standard solution ' $\mathrm{S}$ '. Other different concentrations i.e. $10 \%, 50 \%$, and $100 \%$ respectively were prepared by adding required amount of sterilized $\mathrm{DH}_{2} \mathrm{O}$ for laboratory experiments.

\section{Source of root-knot nematode (Meloidogyne spp.)}

Root-knot nematode, Meloidogyne spp. was collected from the roots of heavily infected tomato plants. Cultures of Meloidogyne spp. were maintained on tomato roots in the greenhouse at the Central Department of Botany, Kirtipur. Egg masses of Meloidogyne spp. were hand-picked using sterilized forceps from heavily infected tomato roots, washed in distilled water and incubated at $28 \pm 2{ }^{\circ} \mathrm{C}$ for $24 \mathrm{hrs}$ for hatching. The hatched juveniles were collected after placing the juvenile suspension through a course sieves $(8 \mathrm{~cm}$ in diameter) containing tissue paper and kept in the petridish with water just deep enough to contact the tissue paper to collect second stage juveniles, so called $\left(\mathrm{J}_{2}\right)$.

\section{In vitro experiment}

The aqueous leaf extract prepared as above was evaluated for nematicidal activity against second stage juvenile $\left(\mathrm{J}_{2}\right)$ of Meloidogyne spp. under laboratory conditions in order to assess the larval mortality. For

Nepalese Journal of Zoology | Online Volume 3 Issue 1 | November 2015 | Page 2 
this experiment, 100 freshly hatched $\mathrm{J}_{2}$ larvae were transferred to $2.5 \mathrm{~cm}$ in diameter plastic petridish containing $10 \mathrm{ml}$ of different concentrations of leaf extract i.e. 10\%, 50\%, and 100\% respectively. The petridish with $10 \mathrm{ml}$ of distilled water (without plant extract) was considered as a control. All the petridishes were maintained at $25 \pm 2^{\circ} \mathrm{C}$ in an incubator.After $12 \mathrm{hrs}, 24 \mathrm{hrs}$ and $48 \mathrm{hrs}$ of incubation, mobile and immobile $\mathbf{J}_{2}$ larvae were counted under stereoscopic microscopic in order to record larval mortality. Immobilized larvae were confirmed by using needle as dead larvae failed to respond to stimulation with a needle. Each treatment was replicated three times.

\section{Statistical analysis}

On the basis of laboratory experiment, the data were recorded as larval mortality (dead or alive). All the data were analyzed according to analysis of variance (ANOVA) using SPSS 17.0 program.

\section{Results}

The percentage of mortality of juveniles of root-knot nematode (100 juveniles used for each experiment) differed with different concentration $(\mathrm{S}=100 \%, \mathrm{~S} / 2=50 \%$, and $\mathrm{S} / 10=10 \%)$ and duration of treatment (12 hrs, $24 \mathrm{hrs,} \mathrm{and} 48 \mathrm{hrs}$ ). Among all the treatment, 100\% of leaf extract proved highly toxic to juveniles followed by $50 \%$ and $10 \%$.

The percentage mortality of $\mathbf{J}_{2}$ of Meloidogyne spp. was $82.6 \%, 36.6 \%$ and 3.3 in $100 \%, 50 \%, 10 \%$ concentrations of leaf extract respectively as compared to control after $12 \mathrm{hrs}$. In other way, out of $100 \mathrm{~J}_{2}$ used in each experiment $17.4 \%, 63.4 \%$ and $96.7 \%$ larvae were remained active in $100 \%, 50 \%$ and $10 \%$ concentration of leaf extract of L. camara as compared to control. Among all the treatment, $100 \%$ of leaf extract proved highly toxic to juveniles followed by $50 \%$ and $10 \%$. Similarly, the percentage mortality of $\mathrm{J}_{2}$ was $89.3 \%, 50.0 \%$ and $16.0 \%$ in $100 \%, 50 \%, 10 \%$ concentrations of leaf extract, respectively as compared to control after $24 \mathrm{hrs}$. In terms of mobilization of larvae, out of 100 larvae used in each experiment $10.7 \%, 50 \%$ and $84 \%$ larvae were remain active in $100 \%, 50 \%$ and $10 \%$ concentration of leaf extract. Likewise, the percentage mortality of $\mathrm{J}_{2}$ was $98.6 \%, 57.6$ and $28.6 \%$ in $100 \%, 50 \%, 10 \%$ concentration respectively as compared to control after $48 \mathrm{hrs}$. In terms of mobilization of $\mathbf{J}_{2}$ larvae, out of 100 larvae, $1.4 \%, 42.4 \%$ and $71.4 \%$ larvae were found active in $100 \%, 50 \%$ and $10 \%$ concentration of leaf extract of $L$. camara. In general, percentage mortality was proportionally correlated with the concentrations and exposure periods of extract. The highest mortality $(98.6 \%)$ was recorded in $100 \%$ concentration of leaf extract at $48 \mathrm{hrs}$ of exposure period followed by $89.6 \%$ in $24 \mathrm{hrs}$ and $82.6 \%$ in 12 hrs (Table 1).

Table 1. Effect of different concentration of plant extract of L. camara on larval mortality after 12, 24 and $48 \mathrm{hrs}$

\begin{tabular}{|l|l|l|l|l|l|}
\hline Plant & $\begin{array}{l}\text { Incubation } \\
\text { period (hrs) }\end{array}$ & \multicolumn{4}{|l|}{ \% of mortality of nematode in different concentrations } \\
\hline \multirow{2}{*}{$\begin{array}{l}\text { Lantana } \\
\text { camara }\end{array}$} & & $\mathrm{S}(100 \%)$ & $\mathrm{S} / 2(50 \%)$ & $\mathrm{S} / 10(10 \%)$ & Control \\
\cline { 2 - 6 } & $12 \mathrm{hrs}$ & 82.6 & 36.6 & 3.3 & 0 \\
\cline { 2 - 6 } & $24 \mathrm{hrs}$ & 89.3 & 50.0 & 16.0 & 0 \\
\cline { 2 - 6 } & $48 \mathrm{hrs}$ & 98.6 & 57.6 & 28.6 & 0 \\
\hline
\end{tabular}

Each value is the mean of three replicates.

Number of second stage juveniles used $=100$ (for each treatment)

Nepalese Journal of Zoology | Online Volume 3 Issue 1 | November 2015 | Page 3 
Result in table 2 also showed that effect of various concentrations of leaf extracts of Lantana camara on larval mortality over exposure time i.e $12 \mathrm{hrs}, 24 \mathrm{hrs}$ and $48 \mathrm{hrs}$. In general, percentage of larval mortality increased with the increase in exposure period but decrease with dilutions. Comparison of treatment mean regarding period of leaf extract of Lantana camara indicated that test plant gave the maximum mortality at $100 \%$ concentration at $48 \mathrm{hrs}$ of exposure showing each treatment significantly different than other. Mortality in control treatment was negligible.

Table 2. Mean number of larval mortality in different concentration at 12, 24 and $48 \mathrm{hrs}$

\begin{tabular}{|l|l|l|l|l|l|l|}
\hline Plant & $\begin{array}{l}\text { Incubation } \\
\text { period }(\mathrm{hrs})\end{array}$ & \multicolumn{4}{|l|}{ Concentrations } & $\begin{array}{l}\text { LSD } \\
(0.05)\end{array}$ \\
\hline \multirow{2}{*}{$\begin{array}{l}\text { Lantana } \\
\text { Camara }\end{array}$} & & $\mathrm{S}(100 \%)$ & $\mathrm{S} / 2(50 \%)$ & $\mathrm{S} / 10(10 \%)$ & & \\
\cline { 2 - 7 } & $12 \mathrm{hrs}$ & $8.26^{\mathrm{a}}$ & $3.67^{\mathrm{b}}$ & $0.33^{\mathrm{c}}$ & & 0.39 \\
\cline { 2 - 7 } & $24 \mathrm{hrs}$ & $8.93^{\mathrm{a}}$ & $5.00^{\mathrm{b}}$ & $1.60^{\mathrm{c}}$ & & 0.53 \\
\cline { 2 - 7 } & $48 \mathrm{hrs}$ & $9.86^{\mathrm{a}}$ & $5.77^{\mathrm{b}}$ & $2.86^{\mathrm{c}}$ & & 0.45 \\
\hline
\end{tabular}

Degree of freedom $(\mathrm{df})=58$

T-value $=2.0017$

\section{Discussion}

In the present studies, various concentrations of aqueous leaf extract of $L$. camara were assessed for nematicidal activity in the laboratory conditions. All the treatments exhibited natural nematicidal potential to varying degree. The result showed significant juvenile mortality potential of plant extract against Meloidogyne juveniles. The nematicidal effect of leaf extract on juvenile mortality of Meloidogyne spp. was concentration dependent i.e. the juvenile mortality decreases with increased extract concentration as the efficacy of the plant extract depends on the concentration and duration of exposure of juveniles to the extract (Mahmood et al. 1997). Among all the concentrations of leaf extract of L. camara tested, 100\% concentration at $48 \mathrm{hrs}$ was found effective in controlling Meloidogyne juveniles. This result agrees with the result obtained by (Akhtar and Mahmood 1994) who reported that water extracts from leaves and root of Mexican marigold and leaves of Lantana reduced the hatching of $M$ incognita eggs significantly. The nematicidal activity of $L$. camara against juveniles of Meloidogyne spp. has also been reported by many authors (Begum et al. 2008, Qamar et al. 2005, Shaukat and Siddiqui 2001). The mortality of juveniles might be due to nematicidal chemicals present in the leaf extract as L. camara contains camaric acid and olenolic acids which may have larvicidal or ovicidal properties.

The findings of the present investigation are not conclusive. Further studies should be conducted in greenhouse and field conditions to assess the nematicidal activity. In comparison to the other countries, very limited work on nematicidal treatment is done in Nepal despite the fact that Meloidogyne spp. cause serious problem limiting the plant productivity of many crops. This work will hopefully fill the gap in this research.

\section{Conclusion}

It was found that $50 \%$ concentration of $L$. camara leaf extract at $48 \mathrm{hrs}$ and above was found deleterious to root-knot nematode. This finding could be important from the point of view of controlling the root-knot nematode without the use of chemical pesticides in view of environmental pollution likely to cause. The control of Meloidogyne spp. by the leaf extracts used in this study might be probably based on a complex mode of action involving multiple mechanisms. Therefore, further studies are needed to characterize the active compounds in the test plant that are nematicidal and possessing complex modes of action.

Nepalese Journal of Zoology | Online Volume 3 Issue 1 | November 2015 | Page 4 


\section{Acknowledgements}

The first author acknowledges gratitude to University Grant Commission (UGC/Nepal) Sanothimi, Bhaktpur, Nepal for providing grant for this research. Thanks to Heads of Central Departments of Biotechnology and Botany for providing necessary facilities in lab and greenhouse.

\section{References}

Akhtar, M. and Mahmood, I. 1994.Control of root-knot nematode by bare root dip in undecomposed and decomposed extracts of neem cake and leaf. Nematological Mediterranean 22: 55-57.

Begum, S., Zehra, S. Siddiqui, B. Fayyaz, S. and Ramzan, M. 2008. Pentacyclic Triterpenoids from the Aerial Parts of Lantana camara and their Nematicidal Activity, Chemistry and Biodiversity 5: 18561866.

Hussey, R. 1985. Host parasite relationships and associated physiological changes. In: An Advanced Treatise on Meloidogyne. North Carolina State University p. 143-153.

Keshari, A.K. 2004.Problem of root-knot nematodes (Meloidogyne) in Nepal. Proceeding of IV Nematology. Conference on Science and Technology p. 2144-2149.

Mahmood, I., Masood, A. Saxena, S. and Hussain, S. 1997. Effect of some plant extracts on the mortality of M. incognita and Rotylenchus reinformis. Acta Botanica Indica7: 128-132.

Manandhar, H. and Amatya, P. 1988. Nematodes disease of crops plants in Nepal. Institute of Agriculture and Animal Science. Nepal.

Qamar, F., Begum, S. Raza, S. Wahab, A. and Siddiqui, B. 2005. Nematicidal natural products from the aerial parts of Lantana camara. Natural Product Research 19: 609-613.

Shaukat, S. and Siddiqui, I. 2001.Lantana camara in the soil changes the fungal community structure and reduces impact of Meloidogyne javanica on Mungbean. Phytopathologia Mediterranea 40: 245-252.

Siddiqui, Z., Iqbal, A. and Mahmood, I. 2001. Effects of Pseudomonas fluorescens and fertilizers on the reproduction of Meloidogyne incognita and growth of tomato. Applied Soil Ecology 16(2): 179-185.

Nepalese Journal of Zoology | Online Volume 3 Issue 1 | November 2015 | Page 5 